\title{
Surgical Residents Preference for Plastic Surgery Specialty
}

\section{Dinesh Kadam ${ }^{1}$}

${ }^{1}$ Department of Plastic and Reconstructive Surgery, A. J. Institute of Medical Sciences and Research Centre, Mangalore, Karnataka, India

Indian J Plast Surg 2021;54:251-252.

A career in plastic surgery is flexible, promising, and prosperous. Despite its vast scope and versatility, its impact on student's interests is not optimum. Few superspecialty courses continue to draw the aspirants and remain high-priority branches. Last year, 20 to $25 \%$ of M.Ch applicants opted for surgical gastroenterology, oncosurgery, and urology, $10 \%$ for plastic and neurosurgery, and $5 \%$ for cardiothoracic vascular surgery (CTVS) and pediatric surgery. ${ }^{1}$ The demand for some specialties has also been declining over the past few years for various reasons. Particularly in CTVS and pediatric surgery, as many as 70 and $40 \%$ of the seats were vacant in 2019.,3 This attrition is alarming which is further compounded by the drawbacks of restricted eligibility criteria of NEET Super-specialty. ${ }^{1}$ The situation is not so dire for plastic surgery; nevertheless, despite the varied career options it provides, only $10 \%$ of of candidates prefer plastic surgery is concerning and calls for critical appraisal and remedial steps. The specialty certainly deserves a good pool of worthy and avid aspirants to develop a robust force of future plastic surgeons. There is a distinct gap between reality and perception among the residents about the specialty. All impediments, stereotypes, and biases enveloping the specialty must be eliminated. It is our collective responsibility to effect the change among the fraternity, students, and society.

\section{Choice of Specialty}

A surgical resident develops a personal interest and insights into subspecialties based on his or her exposure. However, peer opinion and perceptions of specialty influence their choices, creating a high demand for some specialties. Several considerations, such as moderate working hours, work-life balance, short learning curve, ease of owning a setup, job potential in institutions, and high monetary returns, are often placed much above the passion for each subject. Many of these could be rooted in bias; nevertheless, a career in plastic surgery fulfills most of these expectations. It offers diverse career options, such as having an own setup with minimum investments, freelancer surgeon, or prospective academic growth, in institutions. Each subspecialty has vast depth and scope for a full-time career and offers the flexibility of switchover in the long run. The specialty is also gender neutral and preferred equally by both. These unique advantages and spectrum are largely unknown to aspiring students and most of the fraternity.

\section{Reaching Out to Medical Students}

The advocacy for the specialty should be sustained and a long-term strategy. Focusing early on medical students helps them in making informed choices. In the current paradigm, exposure during MBBS is either minimal or not existing at all. There are no elective postings in plastic surgery, though available for other superspecialties in the undergraduate (UG) curriculum prepared by the National Medical Commission. Plastic surgery is missing from the list, indicating an absolute lack of understanding of our specialty even among policymakers. It is well-known that sustained and early exposure during undergraduation is likely to influence their career choice. ${ }^{4} \mathrm{~A}$ first-hand exposure provides an avenue to alter any biases or preconceived notions on specialties. Besides, it is imperative for them to understand the basic tenets of wound management, limb salvage, the importance of treating congenital anomalies, and restoring the function. In the absence of a formal provision of postings, other alternatives need to be explored, such as informal interactions, audiovisual presentations to the internees, and residents. It is also worth exploring options such as Surgical Exploration and Discovery (SEAD) Program. ${ }^{5}$ They need to understand the roadmap to the desired specialty, eligibility criteria, and type of surgical branches, such as MS (Master of Surgery)-surgery or ENT (Ear-Nose-Throat), to enter should they wish to pursue plastic surgery later.

\footnotetext{
Address for correspondence Dinesh Kadam, MS, DNB, MCh, Department of Plastic and Reconstructive Surgery, A. J. Institute of Medical Sciences and Research Centre, Mangalore 575004, Karnataka, India (e-mail: drkadam@yahoo.co.in).
}

DOI https://doi.org/ 10.1055/s-0041-1739031 ISSN 0970-0358

\footnotetext{
(c) 2021. Association of Plastic Surgeons of India.

This is an open access article published by Thieme under the terms of the Creative Commons Attribution-NonDerivative-NonCommercial-License, permitting copying and reproduction so long as the original work is given appropriate credit. Contents may not be used for commercial purposes, or adapted, remixed, transformed or built upon. (https://creativecommons.org/licenses/by-nc-nd/4.0/).

Thieme Medical and Scientific Publishers Pvt. Ltd. A-12, 2nd Floor, Sector 2, Noida-201301 UP, India
} 


\section{Surgery Residents}

A postgraduate surgical resident on rotation is a potential candidate and needs an appraisal about the diverse scope. However, plastic surgery departments exist only in 86 out of 385 colleges, depriving over $77 \%$ of the trainees. Rotation postings in many institutions are often limited to managing trauma, burns, and surgical dressings which is less interesting, rather dissuading. A supervised and structured training module with key principles of reconstruction and clinical examples should be adopted. Encouraging interactive sessions is the most effective method to induce curiosity and interest in the specialty. Unless the students on rotation are engaged meaningfully in the planning, discussions, and learning additional surgical skills, the posting could be counterproductive and an opportunity lost.

\section{Mentorship}

The role of senior faculty as inspiring mentors and role models will attract and drive students to pursue the specialty. As we do not have any formal mentor-mentee relationship program in medical colleges, recognizing potential protégé is difficult. We do have a good pool of luminaries in all sub-specialties who could take up influencers' roles to inspire young medicos in their capacity under the APSI banner. This will help those in the transition phase to sharpen the focus toward specialty selection.

Finally, Unless we make a collective and a conscious effort to reach out to the untapped aspirants and eliminate all impediments, we are certain to lose out to other specialties who have successfully built an aura around them.

\section{Conflict of Interest}

None.

\section{References}

1 Kadam D. NEET super-specialty intake: a paradox of demand and supply or the eligibility? Indian J Plast Surg 2021;54(1):1-3

2 Basak D. Pediatric surgery: is it growing? J Indian Assoc Pediatr Surg 2019;24(2):87-88

3 Bedi HS. Opinion: despite empty seats CTVS still retains its glory. Available at: https://medicaldialogues.in/opinion-despite-empty-seats-ctvs-still-retains-its-glory-dr-hs-bedi?infinitescroll=1/ Accessed September 2, 2021

4 Farid M, Vaughan R, Thomas S. Plastic surgery inclusion in the undergraduate medical curriculum: perception, challenges, and career choice-a comparative study. Plast Surg Int 2017;2017:9458741

5 Hicks KE, Doubova M, Winter RM, Seabrook C, Brandys T. Surgical exploration and discovery program: early exposure to surgical subspecialties and its influence on student perceptions of a surgical career. J Surg Educ 2019;76(5):1248-1257 